\title{
Trends in prostate cancer incidence and mortality in Canada during the era of prostate-specific antigen screening
}

\author{
James Dickinson MBBS PhD, Amanda Shane MSc, Marcello Tonelli MD SM, Sarah Connor Gorber PhD, \\ Michel Joffres MD PhD, Harminder Singh MD MPH, Neil Bell MD SM
}

\section{Abstract}

Background: Widespread use of prostate-specific antigen (PSA) to screen for prostate cancer began in the early 1990s. Advocates for screening assert that this has caused a decrease in prostate cancer mortality. We sought to describe secular changes in prostate cancer incidence and mortality in Canada in relation to the onset of PSA screening.

Methods: Age-standardized and age-specific prostate cancer incidence (1969-2007) and mortality (1969-2009) from Public Health Agency of Canada databases were analyzed by joinpoint regression. Changes in incidence and mortality were related to introduction of PSA screening.

Results: Prior to PSA screening, prostate cancer incidence increased from 54.2 to 99.8 per 100000 between 1969 and 1990 . Thereafter, incidence increased sharply (12.8\% per year) to peak at 140.8/100 000 in 1993. After decreasing in all age groups between 1993 and 1996, incidence continued to increase for men aged less than 70 years, but decreased for older men. Age-standardized mortality was stable from 1969 to 1977, increased 1.4\% per year to peak in 1995 and subsequently decreased at $3.3 \%$ per year; the decline started from 1987 in younger men (age < $60 \mathrm{yr}$ ).

Interpretation: Incidence was increasing before PSA screening occurred, but rose further after it was introduced. Reductions in prostate cancer mortality began before PSA screening was widely used and were larger than could be anticipated from screening alone. These findings suggest that screening caused artifactual increase in incidence, but no more than a part of reductions in prostate cancer mortality. The reduction may be due to changing treatment or certification of death.

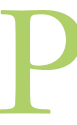
rostate cancer is the most commonly diagnosed non-skin cancer among Canadian men, with an about 1 in 8 lifetime risk of being diagnosed. ${ }^{1}$ Initial detection now occurs commonly from prostate specific antigen (PSA) screening. The PSA test was introduced in $1986,{ }^{2}$ initially for diagnosis and follow-up, then used in Canada and the United States for screening from the early 1990s. ${ }^{3,4}$ Subsequently, there was a dramatic increase in the apparent incidence ${ }^{5}$ of the disease, so that by 2008 these countries had prostate cancer incidence rates among the highest worldwide. ${ }^{6}$ During the same period, mortality from prostate cancer has been decreasing. Advocates assert that PSA screening has allowed earlier diagnosis and treatment, which in turn led to the reductions in mortality. ${ }^{7-9}$

We sought to describe secular changes in the Canadian epidemiology of prostate cancer. In particular, we examine the relation between the onset of PSA screening, prostate cancer incidence and mortality.

\section{Methods}

\section{Data sources}

The numbers of cases and deaths due to prostate cancer, in addition to age-specific and age-standardized incidence and mortality from all Canadian provinces and territories, were obtained from the Canadian Vital Statistics Deaths Database ${ }^{10}$ (1969-2009), as well as the National Cancer Incidence Reporting System (1969-1991) and the Canadian Cancer Registry ${ }^{11}$ (1992-2007). Prostate cancer cases were identified using the International Classification of Diseases for Oncology, 3rd Edition, topography code C61, excluding morphology codes 9050-9055, 9140, 9590-9992. ${ }^{12}$ Deaths due to prostate cancer were identified from the underlying cause of death, classified according to the International Statistical Classification of Diseases and Related Health Problems (8th, 9th and 10th revisions). ${ }^{10}$

Competing interests: All authors were members of the Canadian Task Force on Preventive Health Care or its support group in the Public Health Agency of Canada at the time of writing this paper. All of the authors wrote the task force report on prostate cancer screening.

This article has been peer reviewed.

Correspondence to: James Dickinson, dickinsj@ucalgary.ca CMAJ Open 2016. DOI:10.9778/cmajo.20140079 


\section{Statistical analysis}

Data were categorized by 5 -year age groups at diagnosis and death (45-49 years to $80-84$ years); men older than 85 years were grouped together. Incidence and mortality were calculated by dividing the number of cases or deaths by that year's male population estimates. Rates across all ages were standardized to the 1991 Canadian census population.

The data were imported into Microsoft Excel 2010 for data manipulation and graphing of incidence and mortality trends. The National Cancer Institute's Joinpoint Regression Program 4.0.1 $1^{13}$ was used to measure trends over time, via annual percent change for age-standardized and age-specific rates. This program fits straight-line segments on the loglinear scale to the incidence and mortality data, which meet at joinpoints where the rate of increase or decrease changes. Each joinpoint denotes a statistically significant change in trend. A segment was created between joinpoints, and the gradient was calculated for each segment. Monte Carlo permutation was used to test for significance. Statistical significance was set at $p$ less than $0.05 .{ }^{14}$ This method is routinely used by the Surveillance, Epidemiology and End Results (SEER) program at the US National Cancer Institute for the analysis of trends in cancer rates.

\section{Results}

The age-standardized incidence for prostate cancer almost doubled from 54.2 per 100000 in 1969 to 103.9 in 2013 (Figure 1). Joinpoint regression analysis of the age-standardized incidence (Figure 2) demonstrates an increase of 3.0\% per year from 1969 to 1990 (increase from 54.2 to 99.8 cases per 100 000, respectively). From 1991, the incidence increased to a peak of 140.8 per 100000 in 1993 , followed by a decline between 1993 and 1996. Thereafter, incidence continued its upward trend at a rate similar to the pre-PSA period to a second peak in 2001, then flattened out.

Incidence initially rose with similar time trends for all age groups until 1990 (Figure 3 and Appendix 1 available at www.cmajopen.ca/content/3/4/E73/suppl/DC1). Thereafter, a more rapid increase in incidence was seen until 1993, of similar magnitude for men of all ages. All rates decreased between 1993 and 1996, then incidence again began to increase among younger men (< 69 years) from 1996, whereas decline continued among men 75 years and older. By 2007, incidence was similar for all groups over 65 years of age.

Figure 4 shows that age-standardized prostate cancer mortality was stable from 1969 to 1977 , then increased at $1.37 \%$ per year to peak in 1994, close to the 1993 incidence peak. Thereafter, mortality decreased significantly by $3.25 \%$ per year, or about 1 per 100000 per year from 1994 to 2009 . When analyzed by age group, prostate cancer mortality was consistently higher with increasing age across all years (Figure 5 and Appendix 2 available at www.cmajopen.ca/content/3/4/ E73/suppl/DC1). However, prostate cancer mortality decreased from its peak in 1987 for younger men and progressively later for older men -1994 for the oldest $(\geq 85 \mathrm{yr})$. For men aged $55-80$ years, mortality in 2009 was $21 \%-44 \%$ lower than in 1969, depending on age group. Table 1 shows the rates and reductions by age group.

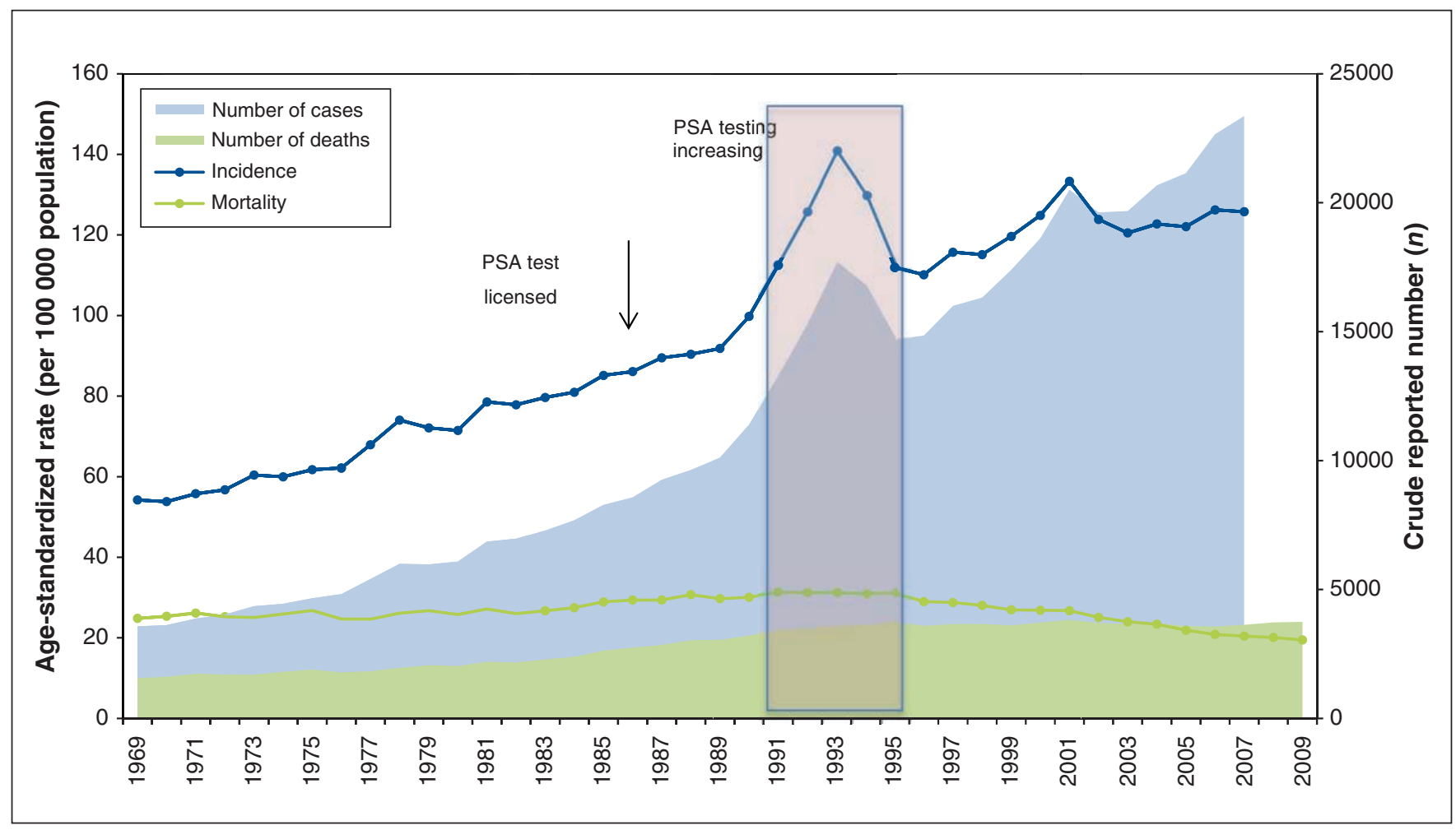

Figure 1: Age-standardized incidence and mortality, number of cases and deaths from prostate cancer, 1969-2009, Canada. 


\section{Interpretation}

The incidence of prostate cancer increased steadily before PSA testing became available, rose rapidly shortly thereafter and has been relatively stable since 2001. Prostate cancer mortality increased until 1994, and has decreased since, with larger proportional reductions observed for men more than 70 years of age than for those aged 70 years or younger. By 2009, 1 in 8 men in Canada could expect to be diagnosed with prostate cancer in their lifetime, and 1 in 28 would die from their cancer. ${ }^{15}$ Furthermore, the rise in incidence now occurs in men 20 years younger, so screened men know of their disease much longer than those who present clinically, ${ }^{16}$ though such lead time may not lead to reduction in overall mortality. Assessing the extent to which the introduction of PSA testing accounts for these trends requires consideration of the context.

The PSA test was initially introduced and licensed in Canada in 1986 to assist in the diagnosis and management of prostate cancer. ${ }^{2}$ In 1991, a seminal paper advocated screening; ${ }^{17}$ in 1992, the American Cancer Society formally supported screening; ${ }^{18}$ in 1994, the PSA test was approved for screening by the US Food and Drug Administration. ${ }^{19}$ Among the Ontario population of around 1.9 million men aged more than 40 years, about 10000 tests were performed in 1988, 50000 in 1990 (when the prostate cancer incidence acceleration began), 180000 in 1993 (the peak of increase in prostate cancer incidence) and 700000 by $2001 .^{3}$ Trends from other provinces appear similar., ${ }^{4,20}$ The Canada Community Health
Survey conducted in 2000-2001 found that nearly half of Canadian men aged 50 years or older had undergone at least 1 PSA test in their lifetime, ${ }^{21}$ although fewer had undergone repeated tests. Among the provinces and territories that asked respondents about PSA screening in subsequent surveys, about $50 \%$ of men aged more than 35 years reported having at least 1 PSA test in their lifetime in 2007-2008, 2009-2010 and 2011-2012.22

The prevalence of undiagnosed (latent) prostate cancer at autopsy is high and increases with age ( $20 \%$ in men aged $40-49 \mathrm{yr}$, increasing to $40 \%$ among men aged $70-79 \mathrm{yr}) .^{23}$ Given that mortality from this disease is about $3 \%$ of all men, ${ }^{15}$ most diagnosed prostate cancer would not develop into harmful disease in a man's lifetime. Overdiagnosis, which occurs when cancer is detected that would not have caused symptoms or death, has been estimated to occur in more than $50 \%$ (and even more than $80 \%$ ) of all diagnosed prostate cancer cases. ${ }^{24-26}$ This finding is consistent with the results shown in Figures 2 and 3, depending on where the baseline for such calculations is taken.

In the pre-PSA screening era, increased diagnosis of cancer was ascribed to increased transurethral resection of the prostate for benign hypertrophy from the 1970s, because these operations provided pathology specimens that led to the discovery of latent cancers. ${ }^{27,28}$ Other factors increasing the diagnosis of cancer in the 1990s included greater use of transrectal or perineal prostate biopsies under ultrasound guidance, ${ }^{29}$ with 6 to 12 or more core biopsy specimens, ${ }^{27}$ and modification of the Gleason grading system, which also led to higher diagnosis rates. ${ }^{30,31}$

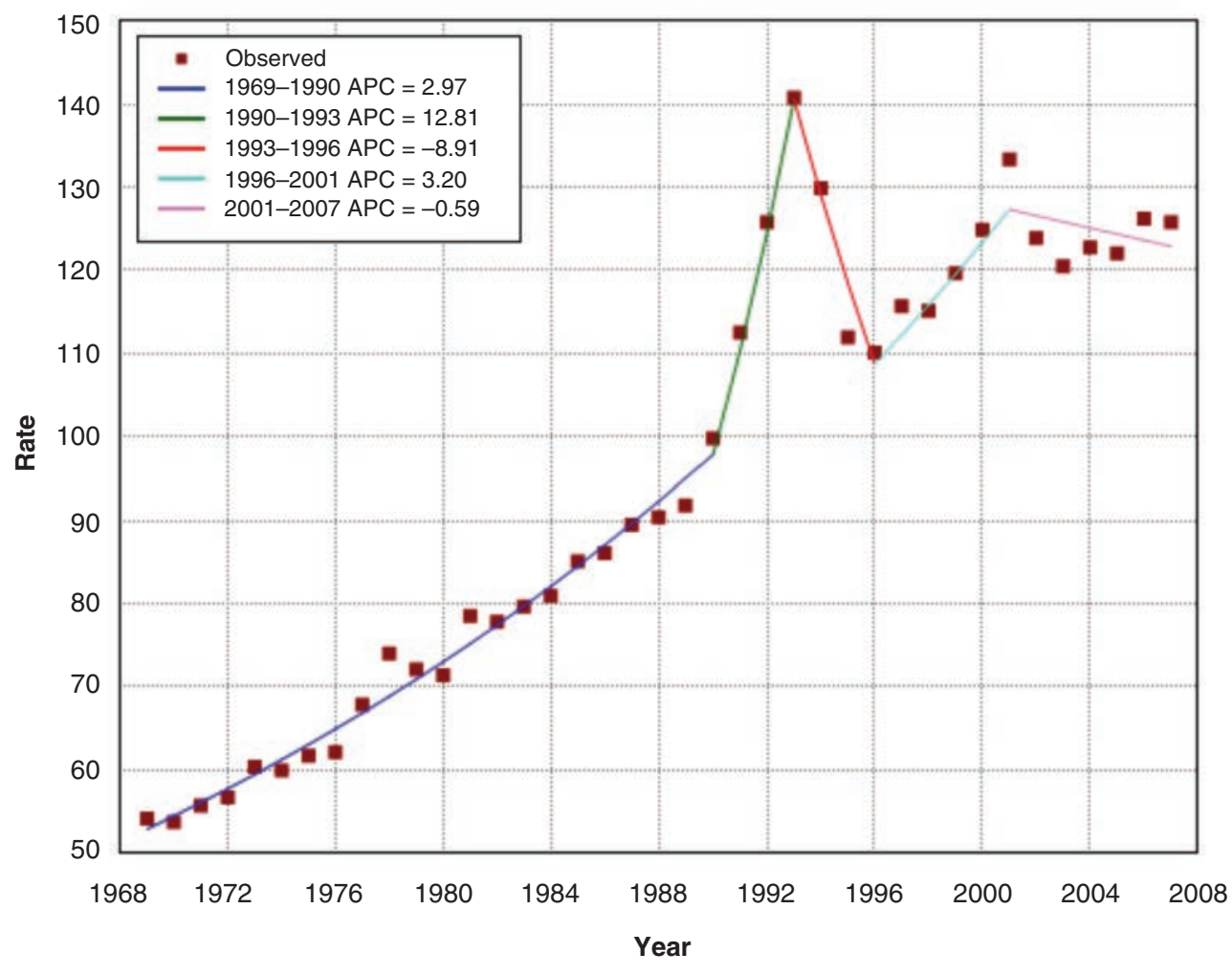

Figure 2: Age-standardized incidence (per 100 000) and annual percent change (APC) of prostate cancer incidence, 1969-2007, Canada. 
The initial peak in the era of PSA suggests that the test was used in high-prevalence populations, revealing prevalent cancers among men being assessed with prostatic symptoms, because PSA was mainly used to investigate urinary symptoms..$^{20,32}$ Thereafter, possibly because this reservoir of symptomatic men already seeing physicians had been depleted (the "harvesting effect"), ${ }^{33}$ incidence decreased, particularly among older men in the later time periods (Figure 3). Transurethral resections declined owing to the introduction of $\alpha$-antagonists and 5 - $\alpha$-reductase inhibitors from $1993,{ }^{27,34}$ so that management of benign hypertrophy largely changed from surgical to medical therapy. Around that time, the PSA test was widely adopted as a screening test. The decrease in transurethral resections of the prostate may account for the apparent reduction in incidence in men over the age of 70 years, in addition to the "harvesting" effect mentioned earlier, whereas increasing PSA screening with the recent emphasis on men as young as 40 years ${ }^{35,36}$ led to apparent increases in incidence among younger men. The peak in 2001 has been attributed to publicity following the diagnosis of then Health Minister Allan Rock ${ }^{37}$

Advocates assert ${ }^{33,36}$ that the decline in prostate cancer mortality is evidence that screening is beneficial - but they provide no explanation for the increase in mortality observed before screening was introduced or for whether the subsequent decline was largely reversal of that effect. However, several other changes in care occurred at that time, including more refined surgical approaches, introduction of antiandrogen therapies, chemotherapy and new modes of radiation treatment. ${ }^{38}$ Increased use of higher-definition computed tomography and ultrasonography enabled better diagnosis and staging. Prostate-specific antigen is not only used for screening, but also for diagnosis and monitoring to detect locally recurrent or metastatic disease before it becomes symptomatic. Thus, it enables better treatment of late-stage disease and potentially delays death, particularly among the oldest age groups, where the disease is most common.

Age-standardized mortality from prostate cancer began declining from 1994 by about 1 per 100000 per year as widespread PSA screening was beginning. These changes are greater than the effects of prostatectomy trials $\left(6.1 \%{ }^{39}\right.$ or $13 \%$ after 10 years in a high-risk subgroup $\left.{ }^{40}\right)$. Pooled results of the European multicentre screening trial (the European Randomized Study of Screening for Prostate Cancer [ERSPC] $)^{41}$ suggest a mortality reduction, detectable 7 years after the start, of 1 per 1000 after 14 years in screened men aged 55 to 69 years. Only 2 of the 7 sites showed any benefit (Netherlands and Sweden). The rest showed no benefit. At best, therefore, mortality reduction of 7 per 100000 per year $(0.1 \% / 14)$ might accrue among screened men aged 65-85 years after 1997. This may account for part of the reduction we saw in some age groups (Table 1). The change was greatest in the oldest age group and was steadily less in younger men. Because only $50 \%$ of Canadian men aged more than 50

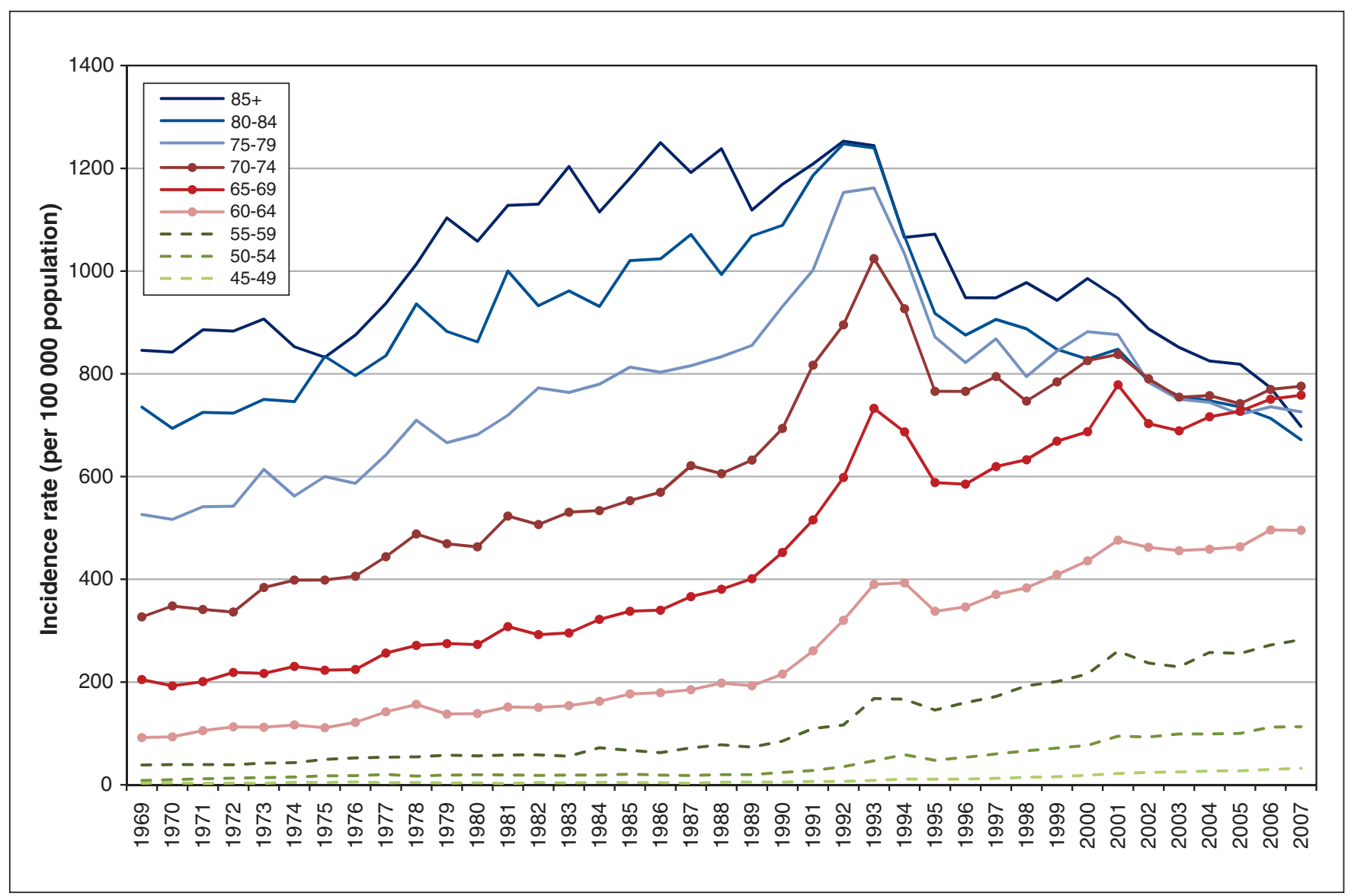

Figure 3: Incidence of prostate cancer by age group, 1969-2007, Canada. 
years had ever had a PSA test by 2001, ${ }^{21}$ and fewer would have undergone regular screening, to reduce overall prostate cancer mortality by $30 \%$, the effect of screening and subsequent treatment would need to be larger than that seen in the ERSPC trial.

Androgen antagonists are a useful adjunct therapy in advanced disease but may increase cardiovascular disease. ${ }^{42-44}$ It is possible that when these agents are used to treat early prostate cancer, this effect increases total deaths, but which are ascribed to cardiovascular disease. Because less than $5 \%$ of men now diagnosed with prostate cancer die from it, ${ }^{33,45}$ even small changes in the cause of death among men who have received treatment for prostate cancer could substantially affect estimates of prostate cancer mortality. In addition, there may be an attribution artifact: in the pre-PSA era, if men had been diagnosed with prostate cancer, the diagnosis was likely to have been included on death certificates, thus causing spurious increases. According to coding rules, deaths from other causes may have been attributed to prostate cancer. As more prostate cancer was diagnosed, it was included on more death certificates. Since PSA use became common, men with a history of prostate cancer but low PSA at the time of death are likely to have prostate cancer listed as an "other significant condition" instead of the underlying cause, as might have occurred previously. ${ }^{42}$ Thus, much of the apparent mortality change could be due to secular changes in the cause of death attributed to men with known prostate cancer.

Although black race appears to almost double risk for prostate cancer, ${ }^{6}$ rates of prostate cancer incidence and mortality vary widely over time and between countries in ways that make biological differences unlikely to be the cause of the variations. ${ }^{6}$ Data from the International Agency for Research on Cancer (Appendix 3, available at www.cmajopen.ca/content/3/4/E73/ suppl/DC1), shows similar increases in incidence in the US, Canada, Australia and New Zealand, where PSA screening was vigorously marketed shortly after its availability. By comparison, European countries show later increases in incidence, which is attributable to later development of PSA screening there. In contrast, these countries had similar increases in mortality before 1990 (Appendix 4, available at www.cmajopen.ca/ content/3/4/E73/suppl/DC1) and reductions afterwards, which suggests there is likely a common factor other than PSA screening. ${ }^{6,46}$ The mortality similarities are probably due to similar temporal trends in treatment patterns and perhaps to death attribution, which suggests that trends in treatment are more important than the potential effect of screening. Some modelling studies also suggest the decrease is caused largely by advances in secondary treatment of late disease, although such conclusions are dependent upon the assumptions made. ${ }^{47}$

\section{Limitations}

This is a descriptive national study using ecological data. These data depend upon the quality of cancer registry data, the completeness and diagnostic quality of pathology for the incidence data and the quality of death certification for the mortality data. At the individual level, we are unable to link PSA testing and diagnosis with treatment and death.

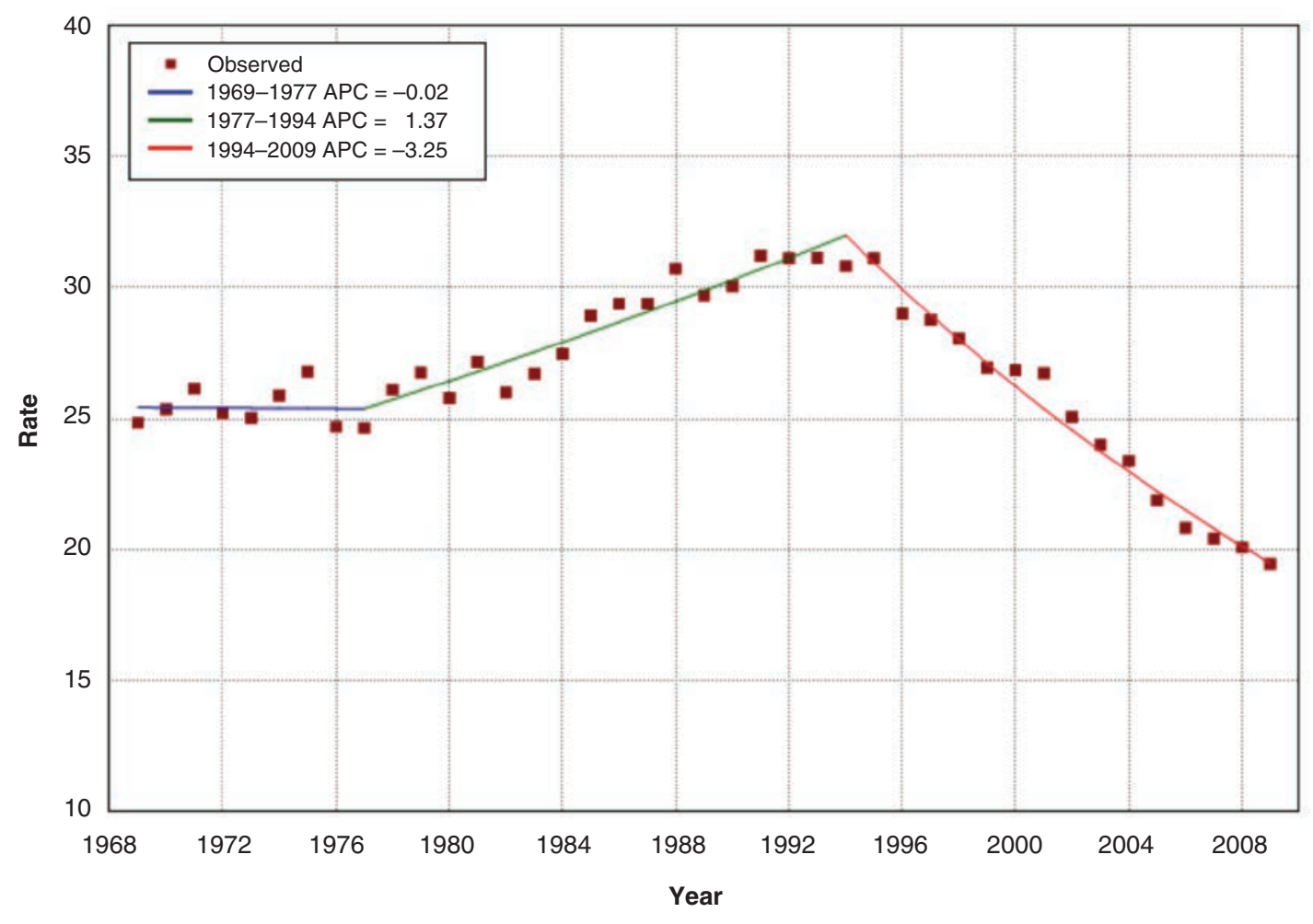

Figure 4: Age-standardized mortality (per 100 000) and annual percent change (APC) of prostate cancer mortality, 1969-2009, Canada. 


\section{Conclusion}

Our findings show that secular changes in prostate cancer incidence began well before PSA screening became widespread after 1995, and declines in mortality began before 1990 and are larger than could be expected from clinical trial data on screening and treatment. Our analysis suggests that the recently observed reductions in prostate cancer mortality in Canada are most likely driven by other factors, such as secular changes in

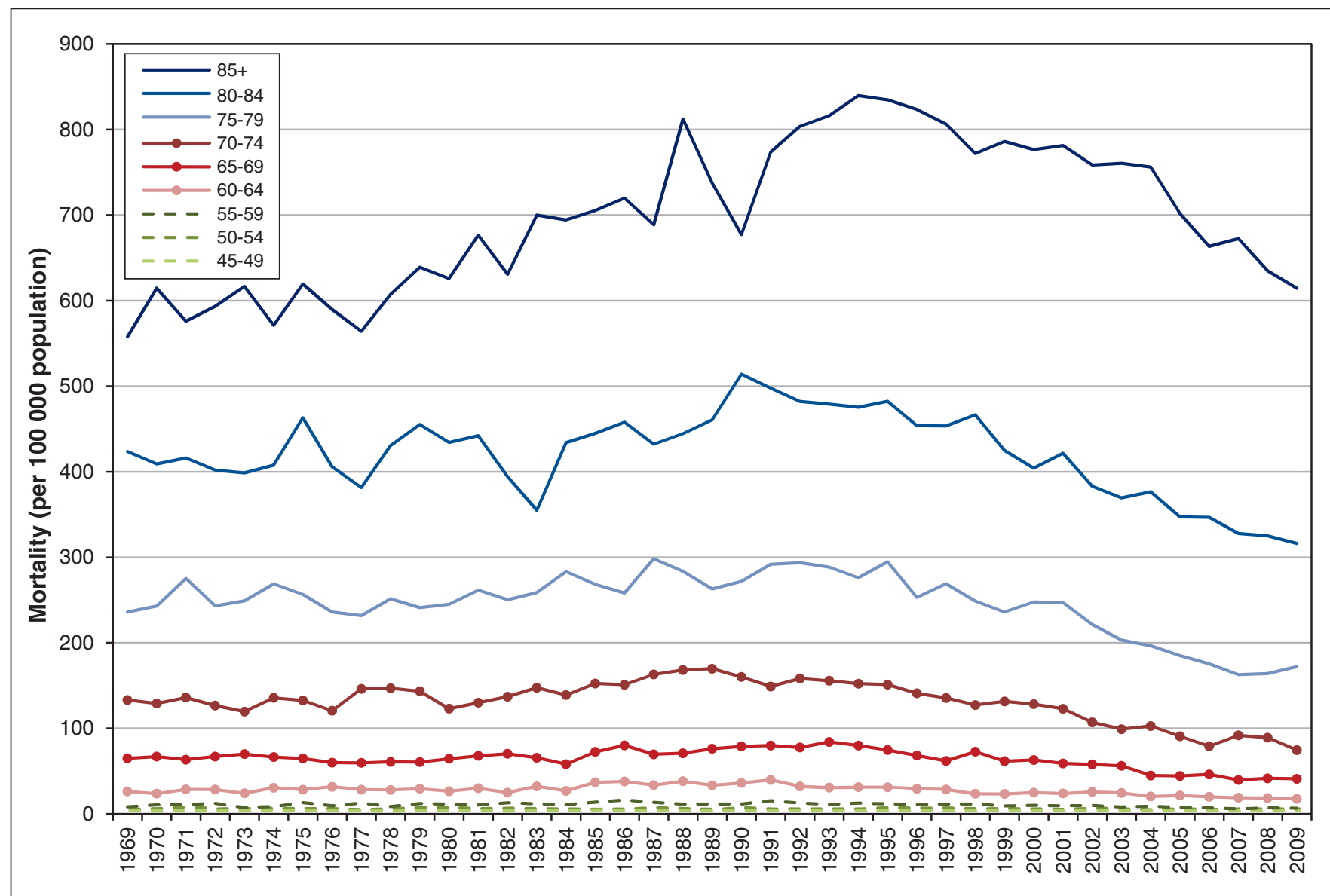

Figure 5: Mortality by age group, 1969-2009, Canada.

Table 1: Prostate cancer age-specific mortality, 1994-2009.

\begin{tabular}{|c|c|c|c|c|c|c|c|c|}
\hline $\begin{array}{l}\text { Age } \\
\text { group, yr }\end{array}$ & Year & $\begin{array}{l}\text { Peak rate } \\
\text { per } 10^{5} \\
\text { population }\end{array}$ & $\begin{array}{l}1994 \text { Rate } \\
\text { per } 10^{5}\end{array}$ & $\begin{array}{c}2009 \text { rate } \\
\text { per } 10^{5} \\
\text { population }\end{array}$ & $\begin{array}{l}15 \text { year rate } \\
\text { difference }\end{array}$ & $\begin{array}{l}\text { Absolute } \\
\text { rate } \\
\text { reduction/ } \\
10^{5} / \mathrm{yr}\end{array}$ & $\begin{array}{c}\% \text { Reduction } \\
15 \mathrm{yr}\end{array}$ & $\begin{array}{l}\% \text { Rate } \\
\text { change/yr }\end{array}$ \\
\hline$\geq 85$ & 1994 & 839.7 & 839.7 & 614.4 & 225.3 & 15.07 & 26.8 & 1.79 \\
\hline 80-84 & 1990 & 514.0 & 475.4 & 316.3 & 159.1 & 10.6 & 33.5 & 2.23 \\
\hline 75-79 & 1987 & 298.4 & 276.1 & 172.2 & 103.94 & 6.9 & 37.6 & 2.50 \\
\hline $70-74$ & 1989 & 169.7 & 152.4 & 74.7 & 77.7 & 5.2 & 51.0 & 3.40 \\
\hline 65-69 & 1993 & 84.2 & 80.0 & 41.1 & 38.9 & 2.6 & 48.6 & 3.24 \\
\hline 60-64 & 1991 & 39.8 & 31.3 & 17.8 & 13.5 & 0.9 & 43.1 & 2.88 \\
\hline 55-59 & 1986 & 16.2 & 12.7 & 6.6 & 6.1 & 0.4 & 48.0 & 3.20 \\
\hline 50-54 & 1971 & 5.3 & 2.8 & 2.7 & 0.1 & 0.0075 & 3.6 & 0.24 \\
\hline 45-49 & 1985 & 1.7 & 0.5 & 0.9 & * & * & * & * \\
\hline
\end{tabular}


treatment practices and possible systematic changes in classifying underlying cause of death, rather than by the limited and uncertain effects of PSA screening.

\section{References}

1. Canadian Cancer Society's Advisory Committee on Cancer Statistics. Canadian cancer statistics 2014. Toronto: Canadian Cancer Society; 2014. Available: www.cancer.ca/ /media/cancer.ca/CW/cancer\%20information/cancer\%20101/ Canadian\%20cancer\%20statistics/Canadian-Cancer-Statistics-2014--EN.pdf?la=en (accessed 2016 Feb. 10)

2. Levy IG. Prostate cancer: the epidemiologic perspective. Can 7 Oncol 1994; 4(Suppl 1):4-7.

3. Bunting PS. Laboratory survey of prostate-specific antigen testing in Ontario updated. Clin Biochem 2004;37:418-21.

4. Skarsgard D, Tonita J. Prostate cancer in Saskatchewan Canada, before and during the PSA era. Cancer Causes Control 2000;11:79-88.

5. McDavid K, Lee J, Fulton JP, et al. Prostate cancer incidence and mortality trends in the United States and Canada. Public Health Rep 2004;119:174-86.

6. Center MM, Jemal A, Lortet-Tierulent J, et al. International variation in prostate cancer incidence and mortality rates. Eur Urol 2012;61:1079-92.

7. 3. evidence supporting PSA testing. Vancouver: BC Cancer Agency; 2012. (accessed 2015 Jan. 26). Available: www.bccancer.bc.ca/health-professionals/ professional-resources/cancer-management-guidelines/genitourinary/prostate \#PSA-Screening (accessed 2016 Feb. 10).

8. Statistics. Toronto: Prostate Cancer Canada; 2013. Available: www.prostate cancer.ca/Prostate-Cancer/About-Prostate-Cancer/Statistics\#.U1V1AMflf2Q] http://www.cua.org/userfiles/files/CUA\%20PCa\%20Screening\%20Guidelines \%20v3\%284\%29.pdf (accessed 2014 Apr. 21).

9. Izawa JI, Klotz L, Siemens DR, et al. Prostate cancer screening: Canadian guidelines 2011. Can Urol Assoc 7 2011;5:235-240.

10. Vital statistics - deaths database. Detailed information for 2011. Ottawa: Statistics Canada; [modified 2013]. Available: www23.statcan.gc.ca/imdb/p2SV.pl? Function =getSurvey\&SDDS=3233\&Item_Id=1635\&lang=en (accessed 2013 July 3).

11. Canadian Cancer Registry. Ottawa: Statistics Canada; 2012. Available: www.statcan .gc.ca/pub/82-231-x/2010001/part-partie1-eng.htm (accessed 2013 July 3).

12. International classification of diseases for oncology, 3rd edition (ICD-O-3). Geneva: The World Health Organization; 2014. Available: www.who.int/classifications/ icd/adaptations/oncology/en/ (accessed 2014 June 24).

13. Joinpoint regression program, version 4.0.4. Bethesda (MD): Statistical Methodology and Applications Branch, Surveillance Research Program, National Cancer Institute; 2013

14. Kim H, Fay MP, Feuer EJ, et al. Permutation tests for joinpoint regression with applications to cancer rates. Stat Med 2000;19:335-51.

15. Navaneelan T, Janz T. Cancer in Canada: Focus on lung, colorectal, breast and prostate. Ottawa: Statistics Canada; [updated 2011]. Cat no 82-624-X. Available: www.statcan.gc.ca/pub/82-624-x/2011001/article/11596-eng.htm (accessed 2015 Jan. 26).

16. Draisma G, Boer R, Otto SJ, et al. Lead times and overdetection due to prostate-specific antigen screening: estimates from the European Randomized Study of Screening for Prostate Cancer. 7 Natl Cancer Inst 2003;95:868-78.

17. Catalona WJ, Smith DS, Ratliff TL, et al. Measurement of prostate-specific antigent in serum as a screening test for prostate cancer. N Engl 7 Med 1991; 324:1156-61.

18. Mettlin C, Jones G, Averette H, et al. Defining the guidelines for the american cancer society cancer-related check-up: Prostate and endometrial cancer. $C A$ Cancer 7 Clin 1993;43:42-6.

19. FDA approves test for prostate cancer. Washington: PRNewswire. 1994 Aug. 29. Available: www.thefreelibrary.com/FDA+APPROVES+TEST+FOR+ PROSTATE+CANCER-a015761756 (accessed 2015 Jan. 11).

20. McGregor SE, Bryant HE, Brant RF, et al. Prevalence of PSA testing and effect of clinical indications on patterns of PSA testing in a population-based sample of Alberta men. Chronic Dis Can 2002;23:111-9.

21. Beaulac JA, Fry RN, Onysko J. Lifetime and recent prostate specific antigen (PSA) screening of men for prostate cancer in Canada. Can 7 Public Health 2006; 97:171-6.

22. Canadian community health survey: public use microdata file (82M0013X): 2007/2008 (cycle 4.1), 2009/2010, 2011/2012. Ottawa: Statistics Canada; [updated 2013]. Available: www5.statcan.gc.ca/olc-cel/olc.action?objId=82M0013X\&obj Type $=2 \&$ lang $=$ en $\&$ limit $=0$ (accessed 2014 July 10).

23. Bell KJL, Del Mar C, Wright G, et al. Prevalence of incidental prostate cancer: a systematic review of autopsy studies. Int 7 Cancer 2015;137:1749-57.

24. Sandhu GS, Andriole GL. Overdiagnosis of prostate cancer. 7 Natl Cancer Inst Monogr 2012;2012:146-51.

25. McGregor M, Hanley JA, Boivin JF, et al. Screening for prostate cancer: Estimating the magnitude of overdetection. CMA7 1998;159:1368-72.

26. Carter JL, Coletti RJ, Harris RP. Quantifying and monitoring overdiagnosis in cancer screening: a systematic review of methods. BM7 2015;350:g7773.
27. Merrill RM, Feuer EJ, Warren JL, et al. Role of transurethral resection of the prostate in population-based prostate cancer incidence rates. Am 7 Epidemiol 1999;150:848-60.

28. Levy IG, Gibbons L, Collins JP, et al. Prostate cancer trends in Canada: rising incidence or increased detection? CMA7 1993;149:617-24.

29. Potolsky AL, Miller AB, Albertsen PC, et al. The role of increasing detection in the rising incidence of prostate cancer. 7AMA 1995;273:548-52.

30. Van der Kwast TH, Roobol MJ. Defining the threshold for significant versus insignificant prostate cancer. Nat Rev Urol 2013;10:473-82.

31. Lucia MS, Bokhoven A. Temporal changes in the pathological assessment of prostate cancer. 7 Natl Cancer Inst Monogr 2012;2012:157-61.

32. Bunting PS, Miyazaki JH, Goel V. Laboratory survey of prostate specific antigen testing in Ontario. Clin Biochem 1998;31:47-9.

33. Klotz L. Active surveillance: the Canadian experience with an "inclusive approach.” 7 Natl Cancer Inst Monogr 2012;45:234-41.

34. Stanford JL, Stephenson RA, Coyle LM, et al. Prostate cancer trends 1973-1995. Bethesda (MD): National Cancer Institute; 1999.

35. Roobol MJ, Bangma CH, Loeb S. Prostate-specific antigen screening can be benefitical to younger and at-risk men. CMAf 2013;185:47-51.

36. Prostate Cancer Canada: PSA recommendation - know your number. Toronto: Prostate Cancer Canada; 2013. Available: http://prostatecancer.ca/ getmedia/f99f7d19-2f3a-44ad-9af9-dc4473b2dc21/PCC-PSA-Position-2014 -final-v2_1.pdf.aspx (accessed 2014 Nov. 1).

37. Fradet Y, Klotz L, Trachtenberg J, et al. The burden of prostate cancer in Canada. Can Urol Assoc 7 2009;3(Suppl2):S102-8.

38. Schroder FH, Roobol MJ. Prostate cancer epidemic in sight? Eur Urol 2012; 61:1093-5.

39. Bill-Axelson A, Holmberg L, Ruutu M, et al. Radical prostatectomy versus watchful waiting in early prostate cancer. N Engl f Med 2011;364:1708-17.

40. Wilt TJ, Brawer MK, Jones KM, et al. Radical prostatectomy versus observation for localized prostate cancer. N Engl 7 Med 2012;367:203-13.

41. Schroder FH, Hugosson J, Roobol MJ, et al. Screening and prostate cancer mortality: results of the European Randomised Study of Screening for Prostate Cancer (ERSPC) at 13 years of follow-up. Lancet 2014;384:2027-35.

42. Haines IE, Gabor Miklos GL. Prostate-specific antigen screening trials and prostate cancer deaths: the androgen deprivation connection. 7 Natl Cancer Inst 2013;105:1534-9.

43. Levine GN, D'Amico AV, Berger P, et al. Androgen-deprivation therapy in prostate cancer and cardiovascular risk: a science advisory from the American Heart Association, American Cancer Society, and American Urological Association: endorsed by the American Society for Radiation Oncology. CA Cancer 7 Clin 2010;60:194-201.

44. Lu-Yao GL, Albertsen PC, Moore DF, et al. Survival following primary androgen deprivation therapy among men with localized prostate cancer. 7AMA 2008;300:173-81.

45. Stephenson AJ, Kattan MW, Eastham JA, et al. Prostate cancer-specific mortality after radical prostatectomy for patients treated in the prostate-specific antigen era. 7 Clin Oncol 2009;27:4300-5.

46. Globocan 2012: estimated cancer incidence, mortality and prevalence worldwide in 2012. Geneva World Health Organization, International Agency for Research on Cancer; 2012. Available: http://globocan.iarc.fr/Pages/fact_ sheets_cancer.aspx (accessed 2014 June 19).

47. Etzioni R, Penson DF, Legler JM, et al. Overdiagnosis due to prostate-specific antigen screening: Lessons from the US prostate cancer incidence trends. 7 Natl Cancer Inst 2002;94:981-90.

Affiliations: University of Calgary Medical Centre, Family Medicine; University of Calgary, Community Health Sciences (Dickinson), Calgary, Alta.; Public Health Agency of Canada (Shane) Ottawa, Ont.; University of Calgary, Cumming School of Medicine; University of Calgary, Office of the Vice President (Research) (Tonelli), Calgary, Alta.; Public Health Agency of Canada, Preventive Health Care Division (Connor Gorber), Ottawa, Ont.; Simon Fraser University (Joffres), Faculty of Health Sciences, Vancouver, BC; Department of Internal Medicine (Singh), University of Manitoba, Winnipeg, Man.; Family Medicine/Public Health Sciences (Bell), University of Alberta, Edmonton, Alta.

Contributors: James Dickinson conceived the article, drafted the manuscript and revised it for important intellectual content; Amanda Shane analyzed the data and contributed to the writing and revising of the manuscript; Neil Bell, Sarah Connor Gorber, Harminder Singh, Michel Joffres and Marcello Tonelli contributed to writing and editing of the manuscript. All of the authors approved the final version to be published and agreed to act as guarantors of the work.

Supplemental information: For reviewer comments and the original submission of this manuscript, please see www.cmajopen.ca/content/4/1/ E73/suppl/DC1 